\title{
Power Quality of Grid Connected Distributed Generation System: Role of FACTS Device
}

\author{
Dattesh.Y.Joshi ${ }^{1}$, Dr.D.M.Patel ${ }^{2}$ \\ Research Scholar, Pacific Academy of Higher Education and Research, Udaipur, India ${ }^{1}$ \\ Professor \& Head, Electrical Engineering Department, Babaria Institute of Technology, Vadodara, India ${ }^{2}$
}

\begin{abstract}
This paper demonstrated of power quality problems associated with the wind turbine based distributed generation systems and how the FACTS device such as UPFC play an important role in power quality improvement of Distributed Generation System. The purpose of the paper is to derive and analyze a reactive power control strategy of UPFC dedicated for DFIG mitigation. The FACT device Unified Power Flow Controller (UPFC) is connected with load bus. Matlab/simulink is used for the work. Paper demonstrated the simulation results for with and without UPFC for Grid connected distributed generation system.
\end{abstract}

Keywords: Power Quality, FACTS, UPFC, Distributed Generation, Grid integration

\section{INTRODUCTION}

Wind turbines produce power fluctuations due to their aerodynamic behavior and wind speed variability, where the wind turbulence influence is indeed the main contribution to voltage fluctuations. Therefore, it would be interesting to know in advance how a group of wind turbines fed into the local distribution network or a large wind farm connected to a high voltage network that may affect the power quality. Power fluctuations play an important role in the evaluation of the impact of wind turbines on the power quality, as stated in the IEC Std 61400-21 which addresses the measurement and assessment of power quality of grid connected wind turbines.[1]

In this paper, it is suggested to use the FACT Device such as Unified Power Flow Controller (UPFC) for grid connected wind farm system to improve the stability in wind farm. Generally, stability means the capability of power system to hold synchronism during occurrence of a severe transient disturbance such as fault in equipment and transmission line or loss of generation or lumped load.

This paper proposes the use of either the Unified Power Flow Controller (UPFC) to improve stability of wind farm that is connected to power system. Firstly, stability analysis of DFIG based on wind turbine is explained.

Furthermore, the wind farm model based on DFIG, equipped with UPFC, connected to power system is developed using MATLAB-SIMULINK. Then the impacts of UPFC on power system during and after fault are investigated. Afterward the effect of ratings of UPFC and the Short Circuit Ratio (SCR) of network on the system recovery is analyzed. Finally, as a conclusion, the performance of UPFC is compared during disturbances.

\section{RIVIEW OF WIND TURBINE SYSTEMS}

There are three types of commonly seen wind turbines: fixed-speed wind turbines with a generator directly connected to the grid, and variable-speed wind turbines with either a synchronous generator with a full power converter in the stator circuit or with a slip-ringed induction generator and a converter in the rotor circuit, as shown in Figs. 1-3, respectively. Fixed speed systems use a squirrel cage induction generator directly connected to the grid. This type of generator needs to be turned at a fixed speed (or within $1 \%$ of rated speed).

A gearbox is used between the generator and turbine shaft to adjust the speed appropriately. In a stall controlled, fixed speed system the blades are firmly bolted to the hub. The pitch angle is set so that the blade will stall and limit the power when the wind speed becomes too high. Often the blade will be slightly twisted so as to gradually stall the blade and ensure smoother transitions, reducing fatigue causing vibrations.

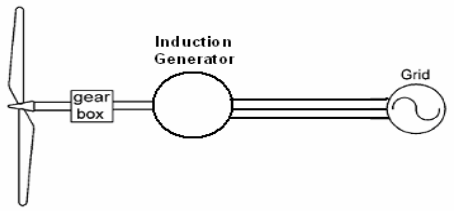

Fig.1 Fixed speed system

The disadvantage of fixed speed systems is that, because the rotor speed must remain fixed, fluctuations in wind speed cause fluctuations in torque. This has the consequence of causing voltage fluctuations on the electrical grid, especially when connected to a weak grid. The shaft pulsations will also result in high stresses on the rotor, shaft, gearbox and generator.

In a variable speed system the generator rotor speed can be changed. By allowing the rotor speed to change, power fluctuations can be more or less absorbed by increasing the speed. Combined with full pitch aerodynamic control, this allows for smoother power output, and a reduction in fatigue on the gearbox and drive train. Variable speed, in some instances can allow for greater energy capture and more efficient operation.

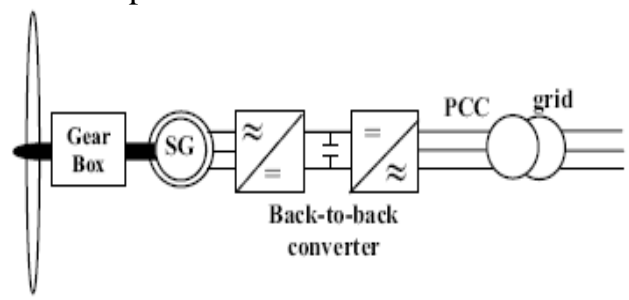

Fig.2 Variable Speed System With Synchronous Generator 
Grid compatibility is achieved by the use of a voltage converter. The converter can be connected between the stator of a synchronous generator and the grid, or between the rotor of a Doubly-Fed Induction Generator (D-FIG) and the stator/grid. Most modern systems will use a D-FIG as the power converter only has to convert the rotor power, which is a fraction of the power of the stator. The D-FIG will be discussed in detail later in this thesis. In a fixed speed system with a squirrel cage generator, a capacitor bank is needed for power factor adjustment. In a D-FIG the use of a voltage converter allows for real and reactive power control. This feature may become more important as the amount of wind capacity on the grid increases. Wind farms may be called on to regulate reactive power. This is already underway in Spain. Another advantage of variable speed operation is that noise levels can be reduced.

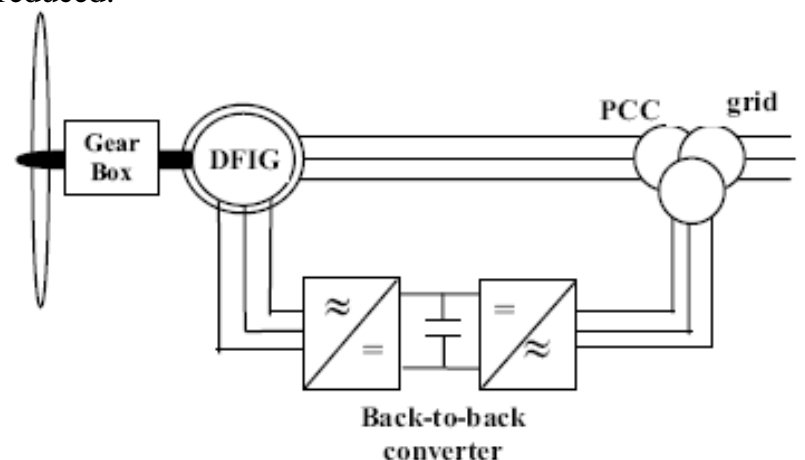

Figure 3.Variable-speed wind turbine with doubly-fed induction generator.

\section{III.INTRODUCTION OF UPFC}

The UPFC is the most versatile FACTS controller developed so far, with all encompassing capabilities of voltage regulation, series compensation, and phase shifting. It comprises of two voltage source converters coupled through a common DC link. The single line diagram is shown in Fig.4.

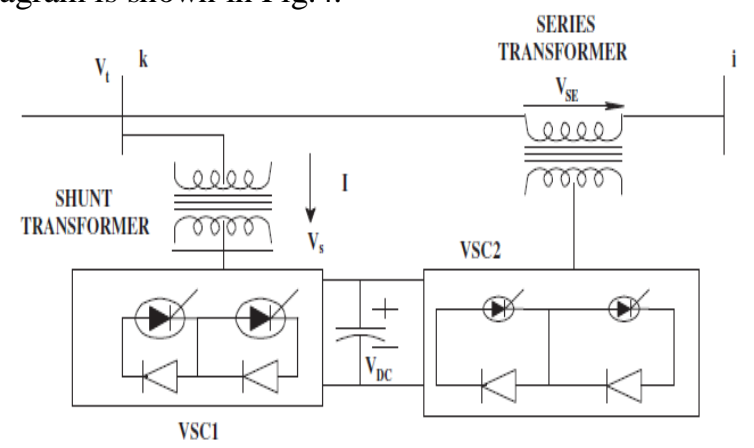

Fig.-4. Single line diagram of UPFC

The active and reactive power flow control loops of the UPFC is shown in Figs. 5 and 6. The stabilizing signal for the unified power flow controller is derived from a power oscillation-damping block, which uses active power flow (Pflow) as the input signal. Pflow Ref is the reference value of active power flow in the line on which UPFC is connected. This value is obtained after running a power flow in the line on which UPFC is to be connected. Vseq is the component of series injected voltage in quadrature with the line current. Qref is the reference setting for reactive power flow in the UPFC connected line and Qflow is the actual reactive power flow in the line and Vsep is the component of AC voltage injected in phase with the line current.

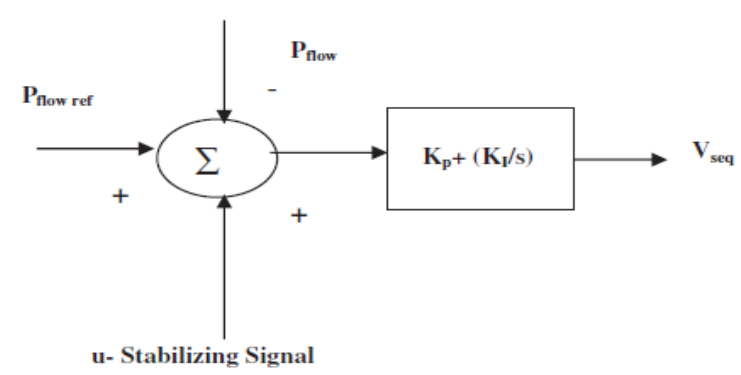

Fig-5. Active Power Flow Loop of UPFC

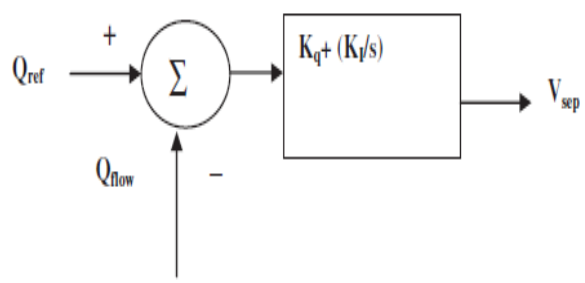

Fig-6.Active Power Flow Loop of UPFC

\section{IV.SIMULATED SYSTEM}

This case study shows a 9-MW wind farm consisting of six 1.5 MW wind turbines connected to a $25-\mathrm{kV}$ distribution system exports power to a $120-\mathrm{kV}$ grid through a $30-\mathrm{km}, 25-\mathrm{kV}$ feeder. A $2300 \mathrm{~V}, 2-\mathrm{MVA}$ plant consisting of a motor load (1.68 MW induction motor at $0.93 \mathrm{PF}$ ) and of a $200-\mathrm{kW}$ resistive load is connected on the same feeder at bus B25. Both the wind turbine and the motor load have a protection system monitoring voltage, current and machine speed. The DC link voltage of the DFIG is also monitored. Wind turbines use a doubly-fed induction generator (DFIG) consisting of a wound rotor induction generator and an AC/DC/AC IGBT-based PWM converter. The DFIG technology allows extracting maximum energy from the wind for low wind speeds by optimizing the turbine speed, while minimizing mechanical stresses on the turbine during gusts of wind. The optimum turbine speed producing maximum mechanical energy for a given wind speed is proportional to the wind speed. For wind speeds lower than $10 \mathrm{~m} / \mathrm{s}$ the rotor is running at subsynchronous speed . At high wind speed it is running at hypersynchronous speed. advantage of the DFIG technology is the ability for power electronic converters to generate or absorb reactive power, thus eliminating the need for installing capacitor banks as in the case of squirrel cage induction generator.

In this case study first we simulated the DFIG based wind farm system with fault and without FACT device UPFC and then we simulated the DFIG based wind farm system with fault and with FACT device UPFC and showed that the improvement and impact of FACT device on the Load Bus. Figures 5 and 6 show the simulation of system with and without FACT device UPFC. 


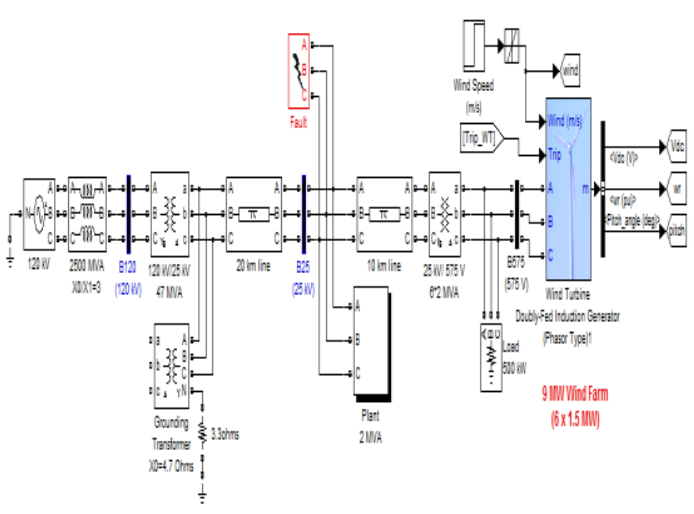

Fig.-7 DFIG wind farm system without UPFC



Fig.-8 DFIG wind farm system with UPFC

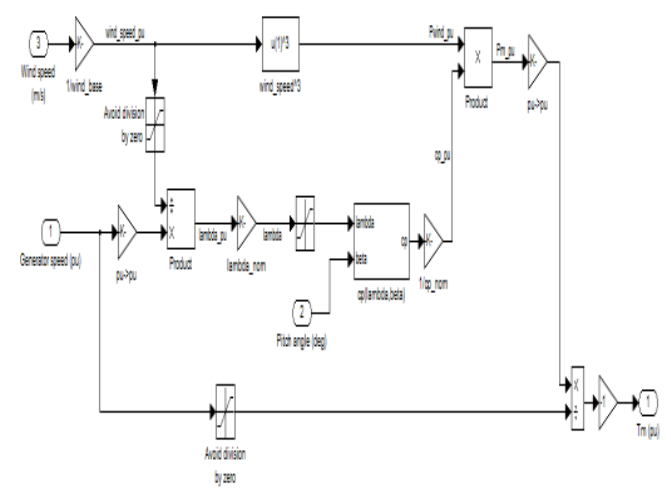

Fig.-9 Model of Wind Turbine

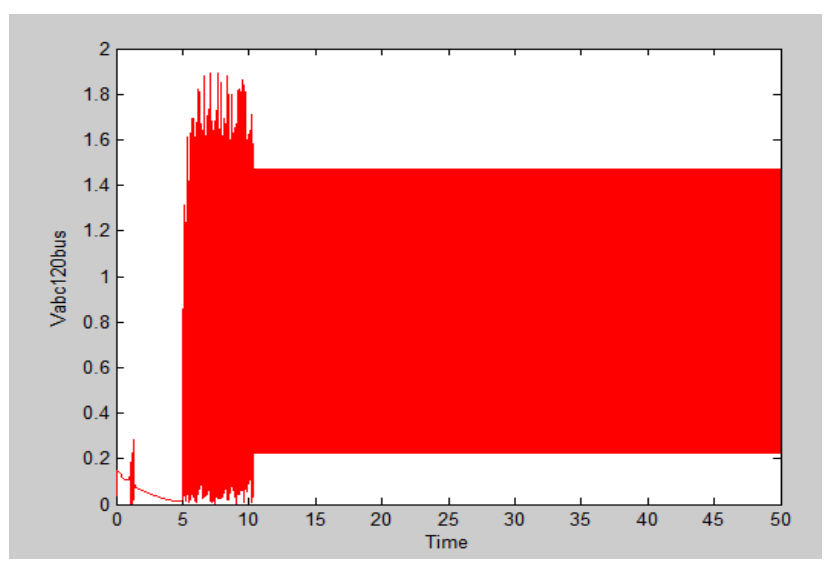

Fig.-10 Vabc120Bus With UPFC

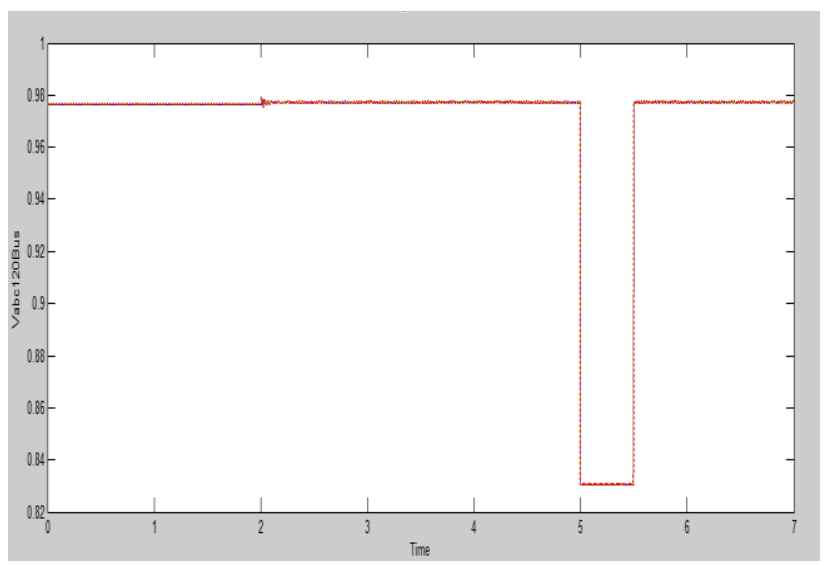

Fig.-11 Vabc Without UPFC

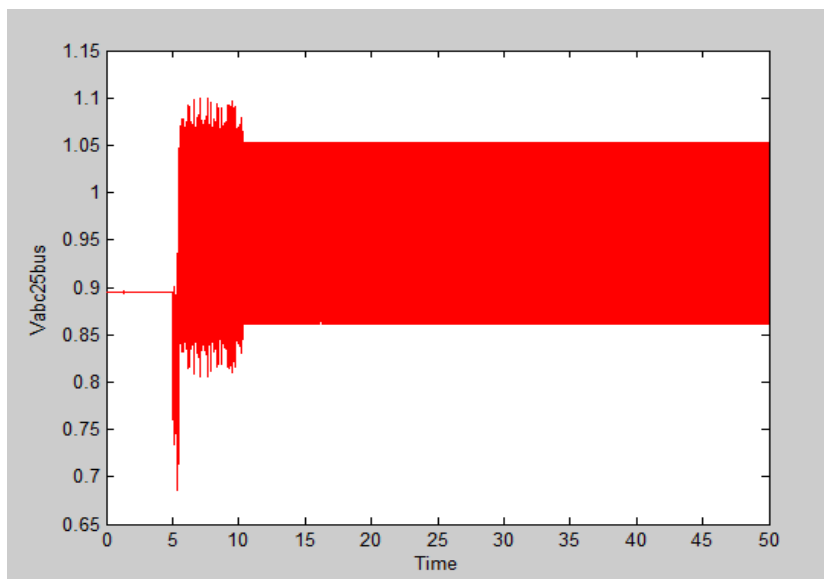

Fig.-12 Vabc25Bus With SSSC

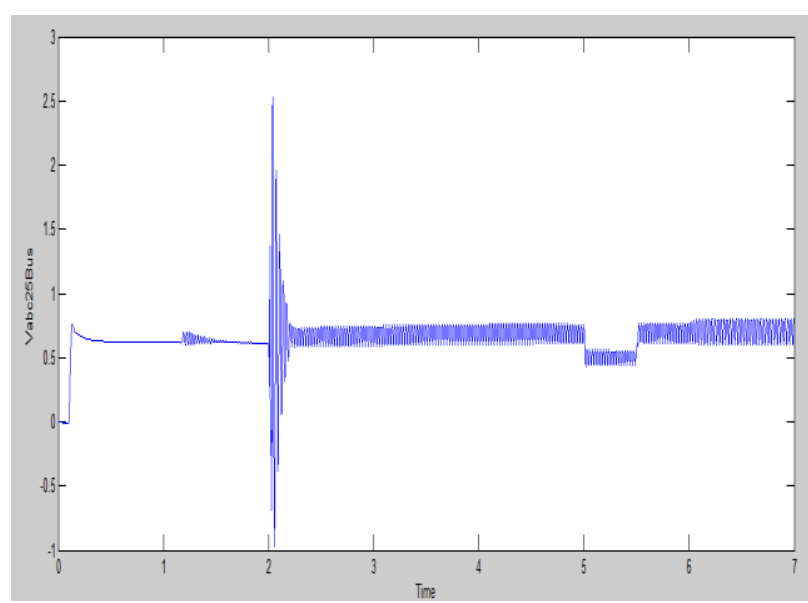

Fig.-13 Vabc25Bus without SSSC

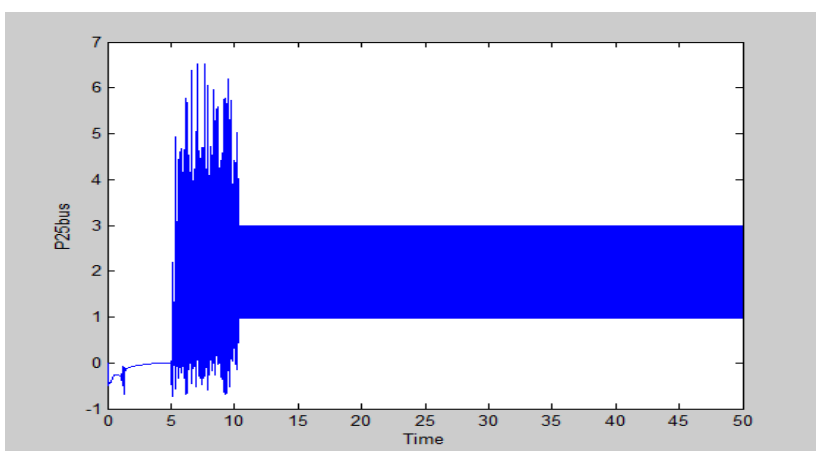

Fig.-14 P25Bus With UPFC 


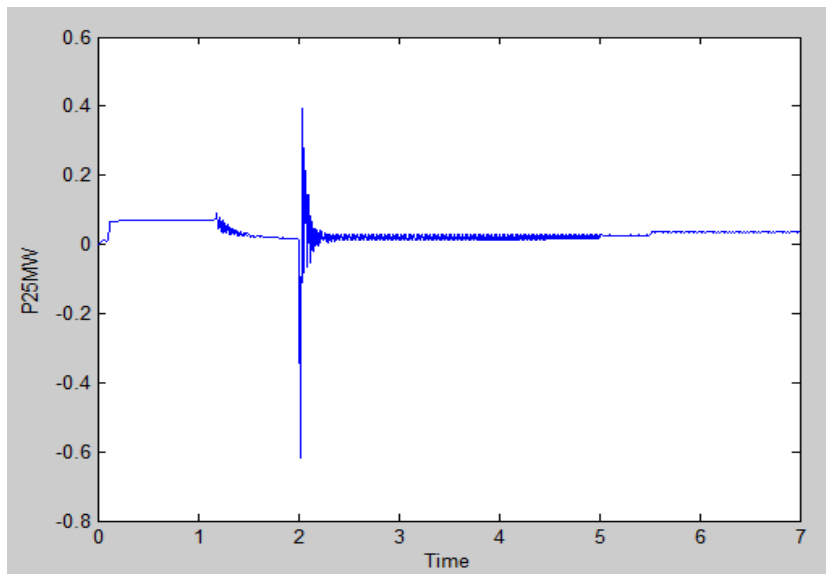

Fig.-15 P25Bus without UPFC

\section{ConClusion}

Paper has demonstrated the performance of DFIG based wind farm system with and without FACT device UPFC. The simulation result showed that voltage of 120bus, Active Power at bus $25 \mathrm{Kv}$, voltage at $25 \mathrm{Kv}$ bus with UPFC has improved then without UPFC under fault conditions in both the cases. So UPFC has improved performance of DFIG based grid connected wind farm system based distributed generation system.

\section{REFERENCES}

[1] Software : MatlabR2009a.

[2] H.J.Su, H.Y.Huang and G.W.Chang"Power quality assessment of wind turbines by Matlab/Simulink". Manwell J. F., McGowan J. G. and Rogers A. L. (2003) Induction machines. Wind Energy Explained (pp.223). Wiley.

[3] T.T.Chuong,"Voltage Stability Investigation of Grid Connected Wind Farm", World Academy of Science,Engineering and Technology, Vol.42,pp.532-536,2008.

[4] L. Holdsworth, X.G. Wu, J.B. Ekanayake, and N. Jenkins, "Comparison of fixed-speed and doubly-fed induction generator wind turbines during power system disturbances", IEE Proc. CGener. Trans. Distrib.,Vol. 150,( 3 ), 2003, pp. 343-352.

[5] N. Senthil Kumar, J. Gokulakrishnan Impact of FACTS controllers on the stability of power systems

[6] connected with doubly fed induction generators/ Electrical Power and Energy Systems 33 (2011) 1172- 1184.

[7] Mohan Mathur R, Varma Rajiv K. Thyristor based FACTS controllers. IEEE Press;2000. 